\title{
Effect of Sclerotial Water Content on Carpogenic Germination of Sclerotinia sclerotiorum
}

\author{
Achala Nepal and Luis E. del Río Mendoza, Department of Plant Pathology, North Dakota State University, Fargo 58108
}

\begin{abstract}
Nepal, A., and del Río Mendoza, L. E. 2012. Effect of sclerotial water content on carpogenic germination of Sclerotinia sclerotiorum. Plant Dis. 96:1315-1322.

The relationship between moisture content and carpogenic germination (CG) of Sclerotinia sclerotiorum sclerotia and the dynamics of sclerotial water imbibition were studied in a controlled environment. The study was conducted using laboratory-produced sclerotia from seven $S$. sclerotiorum isolates. The quantity and rate of water imbibition by three sizes of sclerotia was determined gravimetrically in silty clay, sandy loam, and sandy soils maintained at 100, 75, 50, and $25 \%$ of soil saturation and in distilled water. Smaller sclerotia imbibed water at a significantly faster rate $(P=0.05)$ than larger sclerotia in water and in soil at all saturation percentages. When buried in soil, small, medium,

and large sclerotia were fully saturated within 5,15 , and $25 \mathrm{~h}$, respectively, in all three soil types and moisture percentages. The effect of sclerotia moisture content on CG was evaluated on sclerotia maintained at 95 to 100,70 to 80,40 to 50 , and 20 to $30 \%$ of their water saturation capacity using cool mist humidifiers. Sclerotial moisture content significantly influenced CG $(P=0.05)$. Maximum CG was observed on fully saturated sclerotia, while no CG was observed below 70 to $80 \%$ of saturation. These findings help explain $S$. sclerotiorum's ability to produce apothecia in soils with relatively low moisture levels.
\end{abstract}

Sclerotinia sclerotiorum (Lib.) de Bary is one of the most successful fungal plant pathogens, with more than 400 known plant species from 64 botanical families as hosts $(4,8)$. Losses caused by this pathogen are not restricted to reduced yields (13) but also result from reductions in quality of the produce due to contamination of seed with sclerotia (3) and postharvest attacks in storage facilities (22).

Carpogenic germination (CG) of S. sclerotiorum sclerotia is a crucial event in the life cycle of this pathogen because it allows for sexual recombination $(5,21,31)$ and for production of ascospores, which are considered the primary inoculum for many of the diseases it causes $(1,2,30)$. A thorough understanding of this process, which is heavily influenced by soil temperature and moisture content $(2,3,17,23,34)$, among other factors, could lead to the development of improved disease management strategies and more accurate disease-warning systems.

Numerous studies have been conducted to evaluate the effect of moisture on CG. Sun and Yang (32) evaluated sand moisture contents "at saturation, very close to saturation, and at $50 \%$ of the second moisture level." They concluded that CG was higher when moisture content was closer to saturation. Mila and Yang (23) evaluated the effect of sand moisture content fluctuations on CG; in their study, saturated sand (approximately $-0.1 \mathrm{kPa}$ ) was allowed to dry to -30 to $-40,-60$ to -70 , or -90 to $-100 \mathrm{kPa}$ and then brought back to saturation. This cycle was repeated for the duration of the study. They concluded that moisture fluctuations reduced CG and higher fluctuations were more detrimental than lower fluctuations. A similar result was obtained by Nepal (24), who used soils with textures ranging from sandy to silty clay in a controlled-environment study. In her study, Nepal (24) also observed CG in silty clay soils kept at $-412 \mathrm{kPa}$. Clarkson et al. (12) also studied the effect of soil texture and moisture contents on CG in a controlled environment. In their study, they used peat and silty

Corresponding author: L. E. del Río Mendoza,

E-mail: luis.delrio-mendoza@ndsu.edu

Accepted for publication 2 April 2012.

http://dx.doi.org/10.1094/PDIS-10-11-0889-RE

(C) 2012 The American Phytopathological Society clay loam soils set at moisture contents of -0.2 to $-412 \mathrm{kPa}$. Clarkson et al. (12) did not observe CG when moisture contents were less than $-100 \mathrm{kPa}$. In contrast, field studies $(1,7,9,15)$ have reported CG to occur mostly under very wet conditions (i.e., more than $-20 \mathrm{kPa}$ ). Variations in CG under these conditions has been attributed to the natural variability among isolates without further investigating the effect of sclerotial moisture content on CG or the relationship between sclerotial moisture content and soil moisture content.

Soils act as moisture reservoirs and protect sclerotia from both the sun and weather. Because sclerotia do not have a plant-like vascular system to absorb water, water absorption occurs by imbibition. Therefore, soil texture, structure, and organic matter contents, which are known to affect the soils' ability to retain water (10), could affect the transfer of moisture from soil to sclerotia and, in turn, affect CG. In spite of its importance, the ability of sclerotia to imbibe water from soil and the relationship between sclerotial water content and CG has largely been ignored by researchers. Elucidation of these processes would improve our understanding of why CG also occurs in soils with moisture levels well below saturation and could lead to the development of more accurate models for management of diseases caused by S. sclerotiorum (23). The objectives of this study were to determine (i) the relationship between sclerotial and soil moisture content and (ii) the effect of sclerotial moisture content on CG of sclerotia of S. sclerotiorum.

\section{Materials and Methods}

The ability of $S$. sclerotiorum sclerotia to imbibe water and the effect of sclerotial moisture content on CG were studied in controlled conditions. Water imbibition by sclerotia was measured both in free water and in soils of three different textures maintained at different soil moisture percentages, while the effect of sclerotial moisture content on CG was evaluated in mist chambers.

Isolate preparation. Seven S. sclerotiorum isolates (WM031, WM032, WM080, WM081, WM091, WM107, and WM173) collected from North Dakota fields were used in the study. Isolates were cultured on potato dextrose agar (PDA) in polystyrene petri dishes $\left(9 \mathrm{~cm}\right.$ in diameter) at $21^{\circ} \mathrm{C}$ under continuous light. Multiple agar plugs containing hyphal tips from 5-cm-diameter colonies were transferred into 1-liter conical flasks containing corn meal sand medium (60 $\mathrm{g}$ of white sand, $3 \mathrm{~g}$ of yellow corn meal [Quaker, Chicago], and $16 \mathrm{ml}$ of $0.1 \mathrm{M}$ phosphate buffer, $\mathrm{pH}$ 5.8) 
(18). The cultures were incubated for 30 to 40 days at $21^{\circ} \mathrm{C}$. To facilitate colonization and promote sclerotia production, the medium was stirred weekly using a sterile spatula. Sclerotia were harvested by wet sieving and air dried at $21^{\circ} \mathrm{C}$ for $24 \mathrm{~h}$ before being classified by size using U.S. Standard Brass Test Sieve numbers 4, 8, and 18 (Fisherbrand, Pittsburgh); these sieves have nominal openings of $4.75,2.36$, and $1 \mathrm{~mm}$, respectively. The sieves were stacked with sieve number 8 sandwiched between 4 and 18, and air-dried sclerotia were poured on them. Sclerotia retained in each sieve were considered large, medium, or small, respectively. After sizing, sclerotia were stored at $-5^{\circ} \mathrm{C}$ in petri dishes sealed to avoid contamination and prevent further water loss. At the start of this study, viability of sclerotia was estimated by plating 15 sclerotia from each isolate on PDA and quantifying the percentage of sclerotia that germinated myceliogenically after 3 days of incubation at $21^{\circ} \mathrm{C}$. One month prior to $\mathrm{CG}$ experiments, sclerotia were conditioned for apothecia formation by alternately freezing and thawing them in 24-h cycles for 8 days at temperatures of $-5^{\circ}$ and $21^{\circ} \mathrm{C}$, respectively $(18,25)$. Sclerotia conditioned in this way were used in all studies described below.

Soil mixture preparation and characterization of physical soil properties. Soil collected from the upper 5 in. of a Fargo silty clay and an Aylmer-Bantry fine sand were air dried for 1 week in a greenhouse at approximately $30^{\circ} \mathrm{C}$ and passed through U.S. Standard Brass Test Sieve number 10 (2-mm nominal opening) to screen out plant debris. The soils were then autoclaved at $120^{\circ} \mathrm{C}$ and $103.4 \mathrm{kPa}$ for $45 \mathrm{~min}$. Sterilized soils were mixed in proportions of 1:1 by volume to create an intermediate soil texture, and the three soils were stored for later use. Mechanical analyses of the three soils (soil texture and percentage of silt, sand, and clay contents) were conducted by the North Dakota State University Soil Testing Laboratory in Fargo, ND using the Hydrometer Method (16).

Volumetric water content of all soil mixtures when at 100, 75, 50 , and $25 \%$ of saturation were estimated using the van Genuchten equation $\theta(h)=\theta_{r}+\left(\left[\theta_{s}-\theta_{r}\right] /\left\{\left[1+(\alpha h)^{\eta}\right]^{1-1 / \eta}\right\}\right)$, where $\theta(h)$ represents the volumetric water content $\left(\mathrm{cm}^{3} / \mathrm{cm}^{3}\right)$ of the soil as a function of $h ; h$ represents the water pressure head at which water is extracted from the soil $(\mathrm{cm}) ; \theta_{r}$ and $\theta_{s}$ represent residual and saturated water contents $\left(\mathrm{cm}^{3} / \mathrm{cm}^{3}\right)$, respectively; and $\alpha$ (expressed in $1 / \mathrm{cm}$ units) and $\eta$ are empirical shape parameters (33). These parameters were calculated using the Rosetta software $(28,29)$. Sand, silt, and clay contents (as percentages); bulk density; and water content at 33 and 1,500 $\mathrm{kPa}$ were used as inputs for parameter estimation. Soil bulk density was calculated in the lab by oven drying $50 \mathrm{~g}$ of soil at $110^{\circ} \mathrm{C}$ for $24 \mathrm{~h}$. The volume and mass of oven-dried soil was measured and the bulk density was calculated as a ratio of mass per volume of soil (6). Water content at 33 and $1,500 \mathrm{kPa}$ was estimated using the Pressure Plates Method (27) using a 15-bar Ceramic Plate Extractor (model number 1500; Soil Moisture Equipment Corporation, Santa Barbara, CA) through the services of Agvise Laboratories, Fargo, ND. The gravimetric water content, which is expressed in grams of water per gram of soil, was

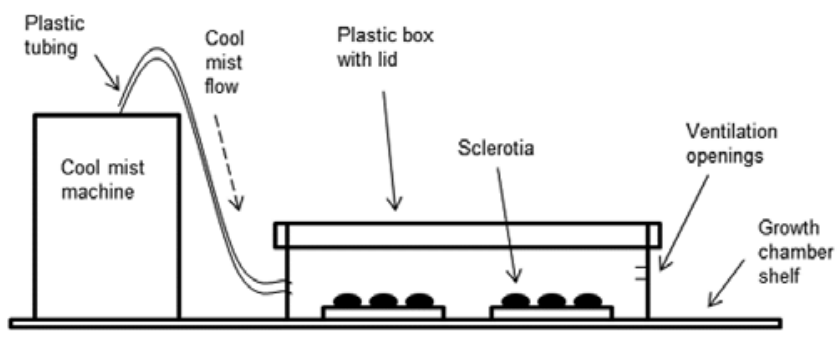

Fig. 1. Diagram of the mist chambers used to study the influence of sclerotial moisture content on carpogenic germination of Sclerotinia sclerotiorum. Cool mist machines were activated periodically to keep sclerotia at moisture percentages required by experimental design. Sclerotia were placed on petri dish bottoms. Moist air flowed from the machine into the box via a clear plastic tube and exited the box on the opposite site through three ventilation openings. Misting chambers were placed in growth chambers for incubation. Diagram was not drawn to scale. calculated for each soil sample, dividing its volumetric water content, estimated by the van Genuchten equation, by the sample's bulk density (6). This allowed the estimation of water contents at $25,50,75$, and $100 \%$ saturation in a sample by weight.

Water imbibition by sclerotia. The rate of sclerotial water imbibition (water uptake) was measured in free water and in soil using a replicated completely randomized design with a factorial arrangement of treatments. Experiments in both environments were conducted at $21^{\circ} \mathrm{C}$ with 10 sclerotia/replication and the experiments were repeated once.

Imbibition in free water was studied using four isolates (WM031, WM080, WM081, and WM091) and three sclerotial sizes (large, medium, and small). Treatments were replicated four times and the entire experiment was conducted twice. The weight of each group of 10 sclerotia was recorded at the beginning of the experiment. Sclerotia were then immersed in $25 \mathrm{ml}$ of distilled water and weighed at 2-min intervals for the first $10 \mathrm{~min}$, every 10 min for the next $50 \mathrm{~min}$, and then at hourly intervals until the weight remained constant. At that time, sclerotia were considered to be saturated. Prior to each weighing, sclerotia were lightly tapped in a paper towel to eliminate water from their surface. The maximum amount of water a sclerotium can absorb was calculated by subtracting the dry weight of sclerotia from its final constant weight and dividing that by 10 .

Water imbibition in soil was also evaluated. Because the isolatesclerotial size interaction in free water was not significant $(P>$ $0.05)$, only large, medium, and small sclerotia of isolate WM031 were used for this study. Water uptake was measured on $200 \mathrm{~g}$ of Fargo silty clay, Aylmer Bantry fine sand, and a 1:1 mix of both that had a loamy sand texture. Treatments were replicated three times and the entire experiment was repeated once. Approximately $200 \mathrm{~g}$ of soil from each type was placed in plastic containers with a lid. Dry weight of 10 sclerotia was measured and then the sclerotia were covered with a single layer of cheesecloth and buried between two layers of soil in the center of each dish. Soils were then moistened to $100,75,50$, and $25 \%$ of their respective saturation capacity by carefully pouring the appropriate amount of water uniformly round the edges of each container and avoiding depositing water directly on sclerotia. Containers were closed to prevent loss of moisture. Sclerotia were taken off the soil to be weighed every hour until a constant weight was obtained. Care was exerted to free sclerotia of soil particles when taking their weight. The process of retrieving, weighing, and returning sclerotia to each container took less than 1 min and the containers were kept closed during the weighing process.

CG in relation to sclerotial moisture content. The effect of sclerotial moisture content on CG was evaluated in moist chambers created using Ziploc plastic boxes ( 25 by 15 by $8 \mathrm{~cm}$; SC Johnson \& Son, Inc., Racine, WI) and cool mist humidifiers (Vicks Ultrasonic Humidifier, model V5100NS; Hudson, NY) (Fig. 1). Several preliminary trials were conducted to identify misting schedules that would maintain sclerotia at 95 to 100,70 to 80,40 to 50 , and 20 to $30 \%$ of saturation. During these trials, the temperature of the chamber was kept at 18 and $14^{\circ} \mathrm{C}$, day and night, respectively, and sclerotia were weighed prior to the start of each run and before and after each misting period for 2 consecutive weeks to confirm that they remained within the desired moisture level. Setting the humidifiers at minimum volume discharge and operating them for 15 min every $6 \mathrm{~h}$ kept sclerotia at 95 to $100 \%$ saturation, whereas operating it for $30 \mathrm{~min}$ every 12,24 , or $36 \mathrm{~h}$ kept sclerotia at 70 to 80,40 to 50 , and 20 to $30 \%$ of saturation, respectively. Once these settings were identified, the experiment was conducted three times. The experiment was organized as a split-split plot design, where moisture levels were considered main plots, isolates were considered subplots, and sclerotial sizes were sub-subplots. During the first two trials, isolates WM031, WM080, WM081, and WM091 were used. In the third trial, isolates WM032, WM107, and WM173 were used. Each experimental unit consisted of 15 sclerotia. Sclerotia were visually inspected every 5 days until the first stipe primordium was observed; then, data on number of sclerotia 
germinated and number of apothecia per sclerotium were recorded every 2 days. A sclerotium was considered to be germinated when stipes were at least $1 \mathrm{~mm}$ in length.

Data analyses. To calculate the rate of water imbibition by sclerotia in water or soil, the amount of water imbibed by sclerotia during different incubation periods was calculated by subtracting the weight of sclerotia at a given time from its initial dry weight. These data were fitted to a modified monomolecular growth model (11). The linearized form of the monomolecular model $[d y / d t=r(1$ $-y)]$ is expressed as $\ln [1 /(1-\mathrm{y})]=\ln \left[1 /\left(1-y_{0}\right)\right]+r_{M} t$, where 1 is a correction factor that represents the upper limit of $y ; y_{0}$ and $y$ represent the amounts of water imbibed at any given period of time with length $t$ and the total amount of water at saturation, respectively, and $r_{M}$ represents the rate of water imbibition in milligrams of water per hour. The treatments were then compared using the general linear model procedure (PROC GLM) of SAS (version 9.2; SAS Institute, Inc., Cary, NC) in these studies and the CG studies. Treatment means were compared using Fisher's protected least significance difference $(P=0.05)$. The Brown-Forsythe test was conducted to determine whether variances between data sets were homogeneous. If variances of the data sets were homogeneous and the interactions between treatments and trials were not statistically significant $(P>0.05)$, a combined analysis was conducted.

\section{Results}

Physical soil properties. The soils used in this study had large differences in their physical properties as well as in their waterholding capacity (Table 1). The soil with the highest content of clay and silt, the Fargo silty clay, had the lowest bulk density and the highest water retention capacity. Further, at saturation $(0 \mathrm{kPa})$, the silty clay soil retained $103 \mathrm{~g}$ of water, which is 1.9 times more water than what was retained by the sandy loam mix $(53.3 \mathrm{~g})$ and three times more water than the sandy soil (33.3 g). The differences in water-holding capacity among soils were even larger when measured at the permanent wilting point $(-1,500 \mathrm{kPa})$. At wilting point, the silty clay soil retained $34.7 \mathrm{~g}$ of water, which is 14 and 2.5 times the amount of water retained by the sandy $(2.5 \mathrm{~g})$ and sandy loam soils ( $14.0 \mathrm{~g})$, respectively. The matric potential in the silty clay soil increased from -22 to $-460 \mathrm{kPa}$, a 21 -fold increase, when soil moisture was reduced from 75 to $25 \%$ saturation. A similar reduction in soil moisture resulted in seven- and fourfold increases in matric potential in the sandy loam and sandy soils, respectively (Table 1). Further, when the moisture content of the silty clay soil was at $50 \%$ of saturation, its matric potential was $-81 \mathrm{kPa}$. At the same moisture content, the matric potential of the sandy loam and sandy soils was -24 and $-19 \mathrm{kPa}$, respectively. At $25 \%$ moisture saturation, the matric potential of the Fargo silty clay soil was $-460 \mathrm{kPa}$, which was 6.5 and 11.8 times larger than that of the sandy loam $(-71 \mathrm{kPa})$ and sandy soils $(-39 \mathrm{kPa})$, respectively.

Sclerotial imbibition in free water. Water imbibition by sclerotia was influenced by their size $(P=0.05)$ but not by their origin (isolate). The monomolecular growth model provided a good fit to the imbibition data, with statistically significant models $(P<$
$0.0003)$ that explained greater than $93 \%$ of the variability observed $\left(r^{2}>0.93\right)$. The rates $\left(r_{M}\right)$ of water imbibition were $0.75,0.48$, and $0.40 \mathrm{mg} / \mathrm{h}$ for small, medium, and large sclerotia, respectively. In all three size categories, water imbibition proceeded at a high rate during the first 2 to $4 \mathrm{~h}$, then declined asymptotically as the sclerotia achieved $100 \%$ of their maximum moisture uptake. Small sclerotia were $100 \%$ saturated in less than $5 \mathrm{~h}$, whereas medium and large sclerotia were saturated in approximately 10 and $15 \mathrm{~h}$, respectively (Fig. 2). By the time sclerotia were saturated, they had doubled in weight regardless of size. Water imbibition was not significantly $(P>0.05)$ affected by isolate-sclerotial size interactions.

Sclerotial imbibition in soil. Sclerotia imbibed water from soil in a manner similar to that in free water; the rate of water imbibition was fast at the beginning when sclerotia were drier, and decreased as sclerotial moisture content increased. The rate of imbibition was unaffected by soil moisture percentage (Fig. 3). In all experiments, sclerotia absorbed more than $70 \%$ of their fully saturated water content within $5 \mathrm{~h}$ of being buried in soil. In all soil types and moisture contents, small, medium, and large sclerotia became fully saturated in $\leq 5,15$, or $25 \mathrm{~h}$, respectively. The monomolecular model provided a good fit to the imbibition data. with statistically significant models $(P<0.0001)$. The rate $\left(r_{M}\right)$ of water imbibition by sclerotia was not significantly affected by soil mois-

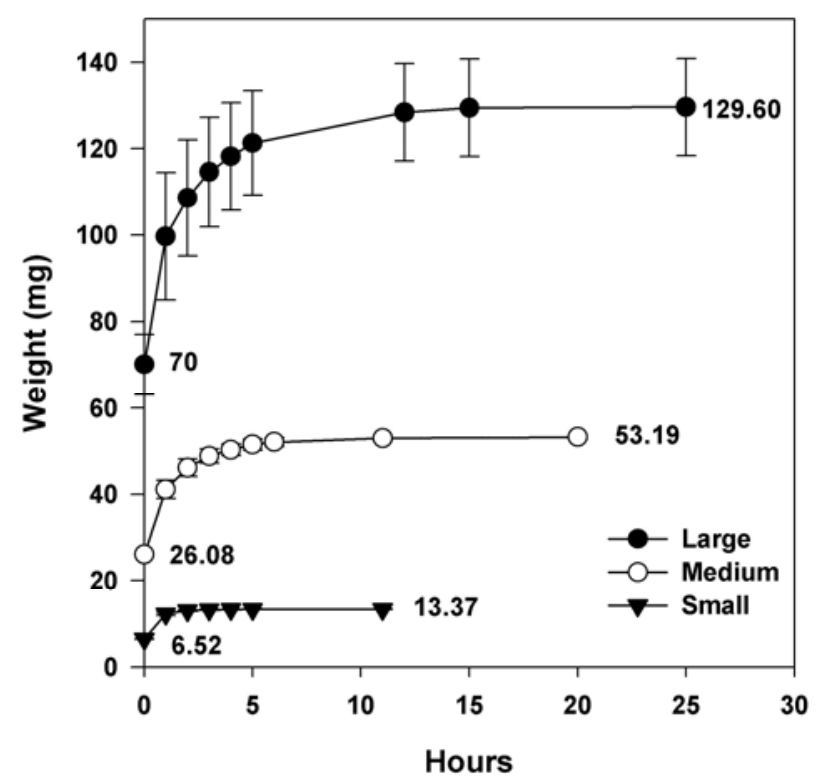

Fig. 2. Effect of size of Sclerotinia sclerotiorum sclerotia on its rate of water imbibition in water. Numbers at the beginning of each curve indicate air-dried weight of sclerotia and numbers at the end indicate the weight of fully imbibed sclerotia. Each data point represents the mean weight averaged across four replications and 10 sclerotia in each replication. Error bars correspond to mean standard error.

Table 1. Gravimetric water content, soil matric potential, and soil textural and physical properties of the two soil types and soil mixture used as the soil substrate for sclerotia imbibition experiments

\begin{tabular}{|c|c|c|c|c|c|c|c|c|c|c|c|c|}
\hline \multirow[b]{2}{*}{ Soil $^{y}$} & \multicolumn{3}{|c|}{ Content (\%) } & \multirow[b]{2}{*}{ Density $\left(\mathrm{g} / \mathrm{cm}^{3}\right)^{\mathrm{z}}$} & \multirow[b]{2}{*}{ Soil texture } & \multicolumn{3}{|c|}{$\begin{array}{l}\text { Water content }(\mathrm{g}) \text { per } \\
\text { matric potential }(\mathrm{kPa})^{\mathrm{w}}\end{array}$} & \multicolumn{4}{|c|}{$\begin{array}{c}\text { Matric potential }(\mathrm{kPa}) \text { per } \\
\text { saturation }(\%)^{\mathrm{x}}\end{array}$} \\
\hline & Sand & Silt & Clay & & & 0 & -33 & $-\mathbf{1 , 5 0 0}$ & 100 & 75 & 50 & 25 \\
\hline Silty clay & 3.8 & 52.3 & 44.0 & 0.77 & Silty clay & 103.0 & 44.2 & 34.7 & 0 & -22 & -81 & -460 \\
\hline Fine sand & 91.9 & 6.9 & 1.3 & 1.27 & Sandy & 33.3 & 4.2 & 2.5 & 0 & -10 & -19 & -39 \\
\hline Soil mixture & 75.8 & 16.1 & 8.2 & 1.12 & Sandy loam & 53.8 & 17.3 & 14.0 & 0 & -10 & -24 & -71 \\
\hline
\end{tabular}

${ }^{\mathrm{w}}$ Gravimetric water content in soils at three different matric potentials per $100 \mathrm{~g}$ of oven-dried soil = volumetric water content/bulk density. Volumetric water content estimated at saturation $(0 \mathrm{kPa})$, field capacity $(-33 \mathrm{kPa})$, and permanent wilting point $(-1,500 \mathrm{kPa})$ using pressure plates.

${ }^{x}$ Soil matric potential of soils at four different percentages of moisture saturations was calculated using Rosetta software on soils kept at $25,50,75$, and $100 \%$ of their water content at saturation.

y Soil types = Fargo silty clay, Aylmer Bantry fine sand, and soil mixture produced by mixing the Fargo and Aylmer Bantry soils at a 1:1 (vol/vol) ratio.

${ }^{\mathrm{z}}$ Bulk density. 
ture content $(P>0.2757)$ and soil texture $(P>0.2869)$ but it was by sclerotial size $(P<0.001)$. The rates of water imbibition by sclerotia across all soil moistures and textures were $0.34\left(r^{2}=0.79\right.$, $P<0.0001), 0.72\left(r^{2}=0.80, P<0.0001\right)$, and $0.83\left(r^{2}=0.80, P<\right.$ 0.0001 ) milligram of water per hour for large, medium, and small sclerotia, respectively. Similarly, significant interactions were detected between soil moisture and sclerotial size $(P<0.0001)$; soil moisture and soil texture $(P=0.053)$; soil texture and sclerotial size $(P=0.0013)$; and soil moisture, soil texture, and sclerotial size $(P<0.0001)$. The rates of water imbibition by small and large sclerotia were relatively insensitive to changes in soil moisture content, whereas the rate of medium sclerotia tended to increase with increased soil moisture content (Fig. 4A). The rate of water imbibition by small and medium sclerotia tended to increase when the soil texture turned sandier but the rate of imbibition by large sclerotia tended to decrease (Fig. 4B).

CG in relation to sclerotial moisture content. The variances of the data sets in first two trials were homogeneous $(P=0.6368)$.
The interactions trial-moisture, trial-size, and trial-moisture-size were not statistically significant $(P=0.4807,0.0741$, and 0.2925 , respectively) in the combined analyses. Isolates and sclerotial moisture contents were the driving forces behind CG. Their main effect and interactions were statistically significant $(P<0.0046)$ in the third run, where multiple isolates were evaluated. In general, isolateWM032 had the highest mean percent CG, with $37.8 \%$ (Table 2). The highest mean CG was obtained when sclerotia were kept at 95 to $100 \%$ moisture saturation in all three runs of the study, followed by 70 to $80 \%$ moisture saturation. CG did not occur when sclerotia were kept at $<70 \%$ of moisture saturation (Table $2)$. Neither the main effect of sclerotial size nor its interaction with sclerotial moisture were significant in any of the trials $(P>$ $0.2215)$, although the latter was significant in the combined analysis $(P=0.0073)$.

The interactions between isolates and sclerotial moisture contents had the strongest influence on CG. Three of the seven isolates (WM080, WM081, and WM091) used in this study did not germi-

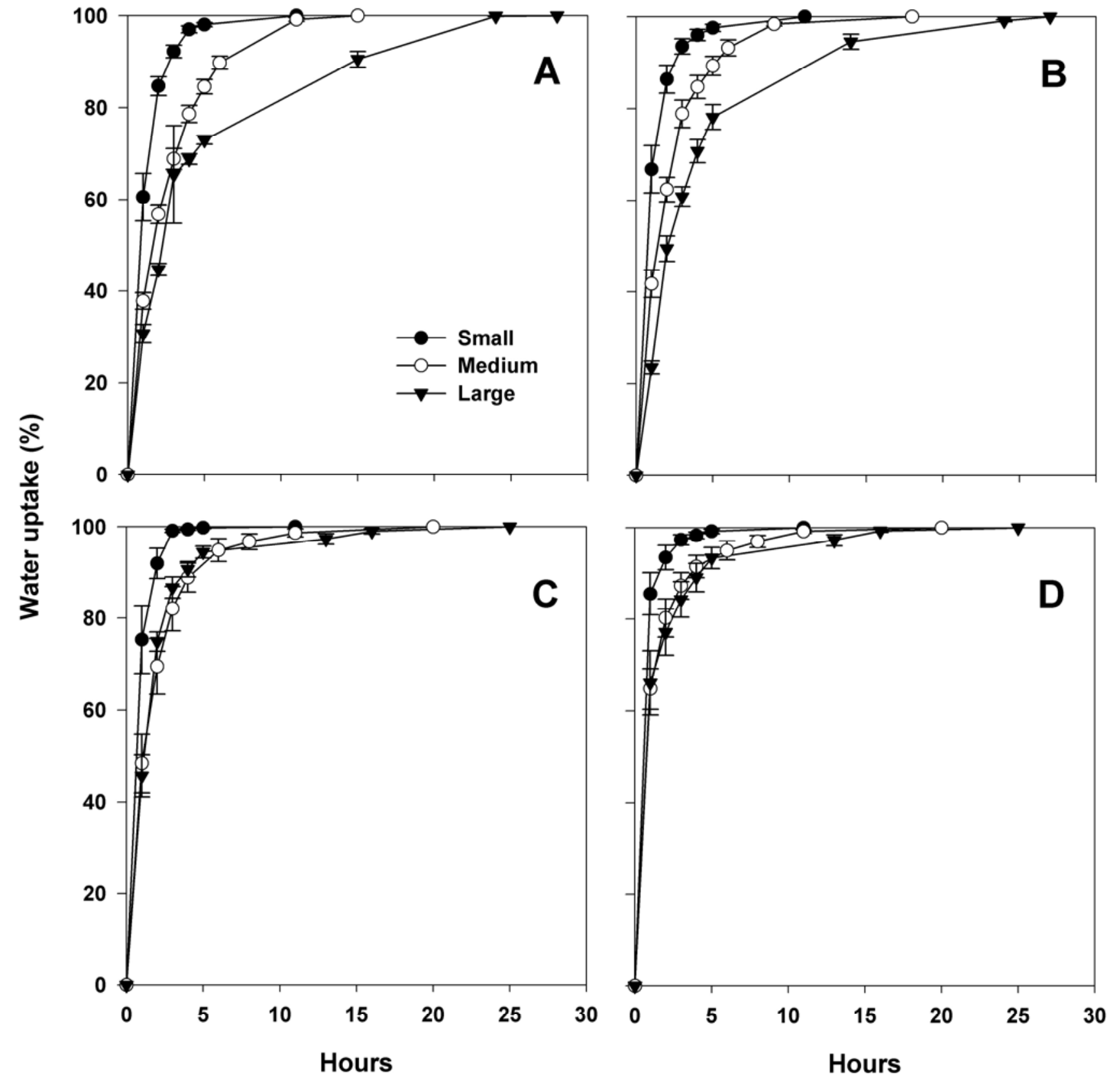

Fig. 3. Effect of soil moisture content on water imbibition by air-dried Sclerotinia sclerotiorum sclerotia. Soil at A, 25\%; B, 50\%; C, $75 \%$; and D, $100 \%$ of saturation. Each data point represents the average of three replications, 10 sclerotia, and three soil textures. Error bars correspond to mean standard error. 
nate carpogenically under any sclerotial saturation percentage. However, when CG occurred, it happened on sclerotia that were kept at $\geq 70 \%$ saturation regardless of the isolate (Fig. 5A and B). Four isolates (WM031, WM032, WM173, and WM107) were responsive to increments in sclerotial moisture contents. However, the level of their response differed. Isolate WM032 was the most responsive, with CG increments going from 0 to $60 \%$ when the level of moisture saturation of sclerotia increased from the 40 to $50 \%$ range to the 70 to $80 \%$ range (Fig. 5B). CG of the other three isolates increased from 0 to an average of $10 \%$ when sclerotial moisture saturation increased from the 40 to $50 \%$ range to the 70 to $80 \%$ range. The largest increase in CG occurred when sclerotial moisture saturation increased from the 70 to $80 \%$ range to the 95 to $100 \%$ range in all isolates but WM107.

The effect of the interactions between sclerotial size and sclerotial moisture saturation levels and between sclerotial size and isolates on CG were significant in the combined analysis of trials 1 and 2 but not in trial 3. In trials 1 and 2, the interaction between sclerotial size and moisture contents was one of magnitude rather than direction. In general, large sclerotia were more responsive to increases in moisture content than the medium and small sclerotia
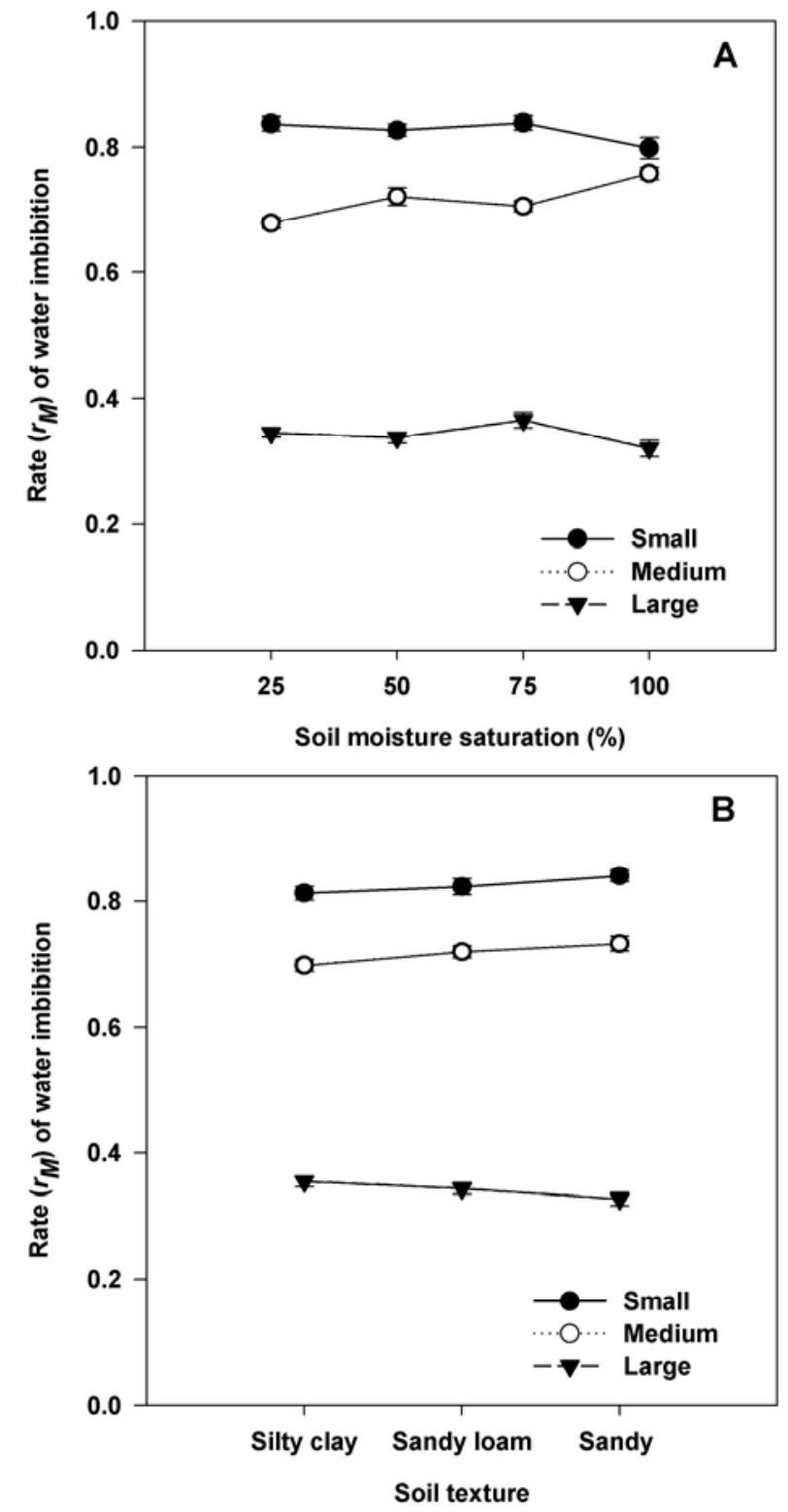

Fig. 4. Effect of the interaction between $\mathbf{A}$, sclerotial size and soil moisture content and $\mathbf{B}$, sclerotial size and soil texture on the rate of water imbibition by Sclerotinia sclerotiorum sclerotia. Error bars correspond to mean standard error.
(Fig. 6A). When kept at 95 to $100 \%$ saturation, CG of large sclerotia was almost twice that of the other two sizes. The response of medium sclerotia to increments in sclerotial moisture content was almost identical to that of smaller sclerotia. In the third trial, all sclerotial sizes reacted in a similar fashion to increases in sclerotial moisture content (Fig. 6B). In all three trials, no germination was observed on sclerotia kept at $<70 \%$ of moisture saturation. Large sclerotia from isolate WM031 tended to have higher CG than smaller sclerotia (Fig. 7A) but that interaction was not significant $(P=0.0817)$ in the third trial (Fig. 7B).

\section{Discussion}

Imbibition of water by $S$. sclerotiorum sclerotia was evaluated in free water and in soils kept at different levels of water saturation. In both environments, $>80 \%$ of the water imbibed by sclerotia was taken up within the first $5 \mathrm{~h}$ of exposure independent of sclerotial size, soil texture, or soil moisture content. Water temperature, while important, does not have an impact large enough as to keep sclerotia from becoming fully imbibed in $\leq 24 \mathrm{~h}$ of exposure (data not shown). Sclerotia became fully imbibed even when buried in soils kept at $25 \%$ of water saturation, a condition that in this study ranged between -460 and $-39 \mathrm{kPa}$. Water imbibition by sclerotia in soils with moisture at less than $25 \%$ were not evaluated in this study, although it would be reasonable to believe that the threshold for water imbibition would not be far below this moisture percentage. The monomolecular growth model (11) provided a good fit to sclerotial water imbibition data in both environments (water and soil), with $r^{2}$ values $>0.95$. The rate of imbibition was initially high and then declined asymptotically as sclerotia achieved $100 \%$ of their maximum moisture uptake. The rates $\left(r_{M}\right)$ of imbibition calculated in this study were inversely related to the size of sclerotia, a relationship that could be explained, in part, by their differences in surface/volume ratios. If one assumes that sclerotia were perfectly spherical, the surface/volume ratio of a small sclerotium would have been approximately 2.4 and 4.8 times that of a medium

Table 2. Effects of isolate, sclerotial size, and moisture content on carpogenic germination of sclerotia of Sclerotinia sclerotiorum

\begin{tabular}{lcc}
\hline & \multicolumn{2}{c}{${\text { Germination }(\%)^{\mathbf{x}}}$} \\
\cline { 2 - 3 } Variables $^{\mathbf{y}}$ & Trials 1 and 2 & Trial 3 \\
\hline Isolates & & \\
WM031 & 11.9 & - \\
WM032 & - & $37.8 \mathrm{a}$ \\
WM107 & - & $6.7 \mathrm{~b}$ \\
WM173 & - & $11.1 \mathrm{~b}$ \\
$P>F$ & - & 0.0004 \\
LSD & ND & 13.8 \\
Size & & \\
Small & 9.4 & 19.4 \\
Medium & 9.7 & 18.9 \\
Large & 16.4 & 17.2 \\
$P>F$ & 0.2215 & 0.8102 \\
LSD & NS & NS \\
Moisture $(\%)^{\mathrm{z}}$ & & \\
20-30 & $0.0 \mathrm{~b}$ & $0.0 \mathrm{c}$ \\
40-50 & $0.0 \mathrm{~b}$ & $0.0 \mathrm{c}$ \\
$70-80$ & $7.0 \mathrm{~b}$ & $27.4 \mathrm{~b}$ \\
$95-100$ & $40.4 \mathrm{a}$ & $46.7 \mathrm{a}$ \\
$P>F$ & 0.0035 & 0.0008 \\
LSD & 11.1 & 15.6 \\
\hline
\end{tabular}

${ }^{\mathrm{x}}$ Dash $(-)=$ isolate not used in this trial, ND $=$ no data, and NS $=$ not significant. The third trial was conducted with a different set of isolates. Data for sclerotial size for trials 1 and 2 were combined for analysis because variances were homogeneous $(P=0.6368)$, no interactions were present $(P=0.0741)$, and trials were not significantly different $(P=$ $0.1327)$. Data for sclerotial moisture content for trials 1 and 2 were combined for analysis because variances were homogeneous $(P=0.6368)$ and no interactions were present $(P=0.4807)$.

${ }^{y} P>\mathrm{F}=$ the probability associated with the $F$ value and LSD $=$ Fischer's protected least significant difference at $\alpha=0.05$.

z Sclerotial moisture content from saturation. 
and large sclerotium, respectively. Similarly, a large sclerotium had a roughly 2.7 and 10.7 times larger mass than a medium and small sclerotium, respectively, and could hold almost that much water.

The highest CG was observed on fully saturated sclerotia, which is a result that is in agreement with field observations of apothecia occurring in very wet fields $(1,7,9,15)$ and results of laboratory studies in which sclerotia were incubated in water-saturated substrates (32) or soil-less environments (34). This is the first time, however, that the association between sclerotial moisture content and CG has been studied. No CG was observed on sclerotia kept below 70 to $80 \%$ moisture saturation. This saturation percentage could be considered the threshold for CG. Myceliogenic germination (MG) of S. sclerotiorum sclerotia, which is an asexual form of reproduction of this pathogen, is also influenced by sclerotial moisture content although no direct evidence, to our knowledge, has been published. Huang et al. (19) observed that MG was highest when sclerotia were incubated in environments with $100 \%$ relative humidity $(\mathrm{RH})$, whereas only marginal MG levels were observed when sclerotia were incubated in an $85 \% \mathrm{RH}$ environment. Although it may be logical to assume that sclerotia kept in $100 \% \mathrm{RH}$ would eventually reach saturation, incubation at $85 \% \mathrm{RH}$ does not necessarily imply sclerotia would imbibe water up to $85 \%$ of saturation.

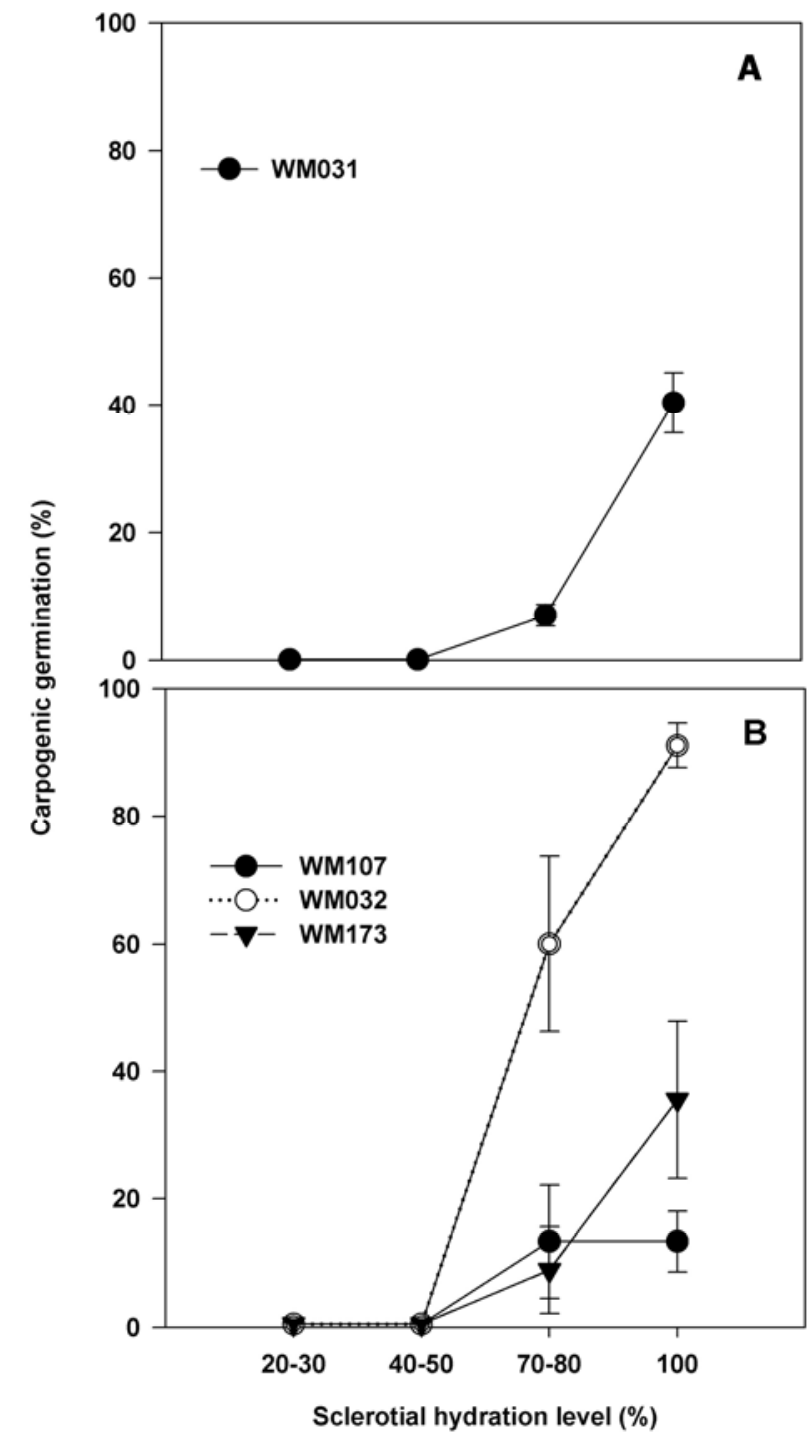

Fig. 5. Effect of the interaction between Sclerotinia sclerotiorum isolates A, WM031 and B, WM107, WM032, and WM173 and four sclerotial moisture percentages on carpogenic germination. Error bars correspond to mean standard error.
Three of the four isolates used in the first two trials failed to germinate carpogenically at any level of sclerotial moisture saturation. Sclerotia used in these studies had $>96 \%$ viability and had been conditioned for CG using a methodology successfully applied to produce ascospores of $>50$ other $S$. sclerotiorum isolates collected from North Dakota (L. E. del Río, personal communication). The lack of uniform response to induction of $\mathrm{CG}$, which is characteristic of $S$. sclerotiorum, has been attributed by other researchers to several factors, including temperature, length and type of conditioning period $(14,23)$, geographical origin of the isolates (20), and nutritional level of the sclerotia (25), among others. Nevertheless, whenever CG was observed in this study, it occurred only when sclerotia were kept at $>70 \%$ of moisture saturation.

The ability of sclerotia to reach and maintain moisture saturation even in soils kept at $25 \%$ saturation helps explain why CG could occur in soils with relatively "low" moisture content $(12,24,34)$. We hypothesize that any amount of water in excess of the $25 \%$ soil saturation would facilitate the germination process by removing potential inhibitors that may be present in sclerotia (14). Thus, the differences in the amount of CG observed between soils with constant and fluctuating moisture conditions $(23,24)$ would be caused

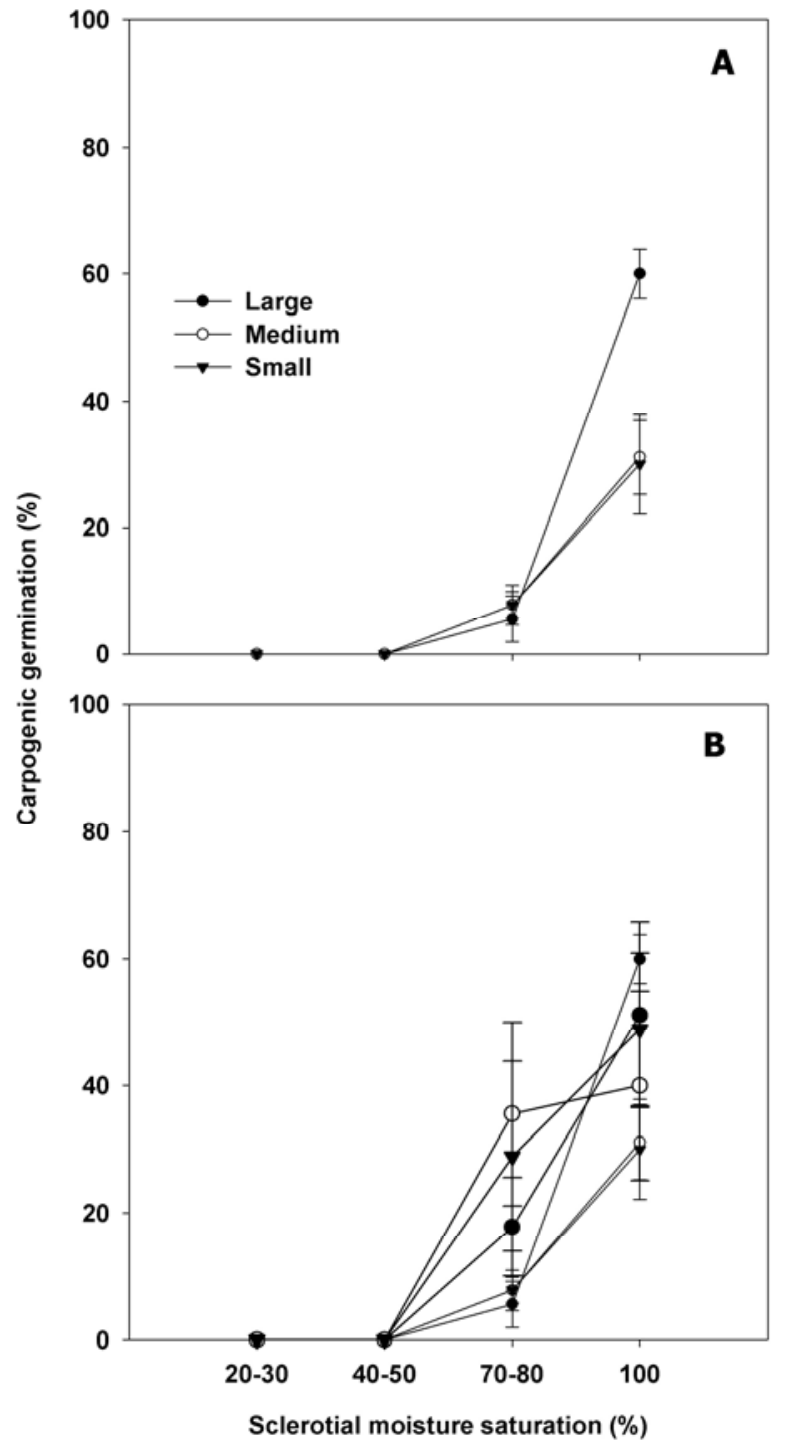

Fig. 6. Effect of the interaction between three sclerotial sizes and four levels of sclerotial moisture percentages on carpogenic germination of Sclerotinia sclerotiorum sclerotia. A, Each data point represents the average germination of isolate WM031; B, each data point represents the average of three other isolates. Error bars correspond to mean standard error. 
by differences in the rate at which these inhibitors may be removed, especially in cases when soil moisture fluctuations do not go below $25 \%$ of saturation. It is possible that sclerotia could maintain high moisture percentages for short periods of time even if soils dry below the $25 \%$ saturation. In such situations, the length of the periods with "low" moisture would be as important or perhaps more important than the degree of dryness reached. Keeping soils at $\geq-80 \mathrm{kPa}$ for 10 to 20 days "arrested CG and reset the clock of germination" (34), whereas allowing soils to dry down to $-460 \mathrm{kPa}$ and rewetting them immediately reduces CG but does not arrest it or reset its clock.

The ability of $S$. sclerotiorum sclerotia to undergo $\mathrm{CG}$ even when hydrated only up to 70 to $80 \%$ of its moisture saturation capacity suggests that CG could take place in soils with less than $25 \%$ of water saturation. Detection of S. sclerotiorum ascospores in fields under dry conditions supports this conclusion (26). The ability to germinate even in low moisture conditions is a survival trait that could help perpetuate the species; after all, a single $S$. sclerotiorum sclerotium is capable of releasing millions of ascospores (30) and a few of them could succeed in infecting a host. However, the CG levels observed under such conditions might not cause significant economic losses to growers or justify the use of fungicides. Results of this study explain, in part, the ability of $S$. sclerotiorum to germinate carpogenically in rather dry conditions; however, the

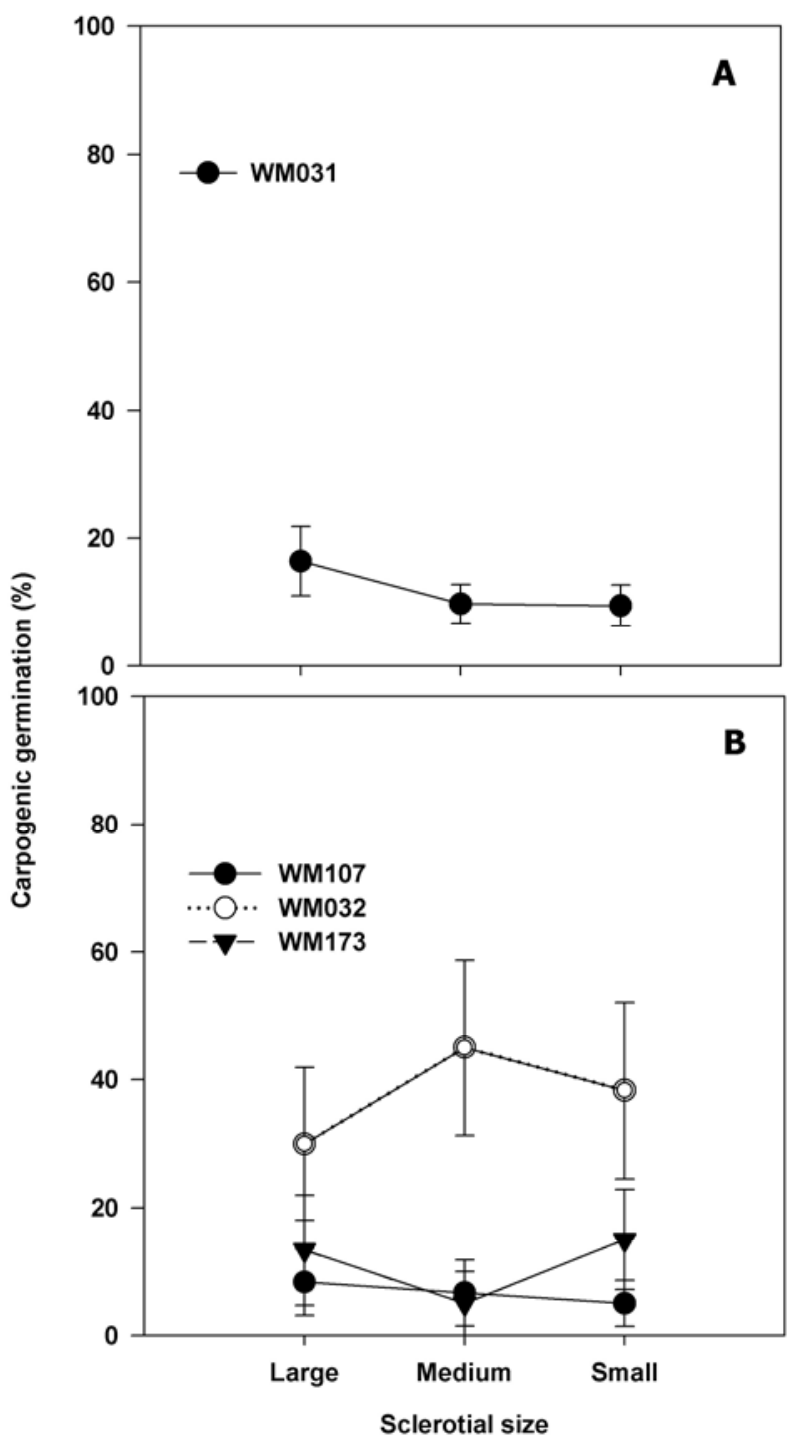

Fig. 7. Effect of the interaction between Sclerotinia sclerotiorum isolates A, WM031 and B, WM107, WM032, and WM173 and sclerotial size on carpogenic germination. Error bars correspond to mean standard error. physiological mechanisms associated with the germination process are still not clear and deserve additional attention.

\section{Acknowledgments}

This project was funded by the U.S. Department of Agriculture-ARS Sclerotinia Initiative Program (cooperative agreement 58-5442-5-289).

\section{Literature Cited}

1. Abawi, G. S., and Grogan, R. G. 1975. Source of primary inoculum and effects of temperature and moisture on infection of beans by Whetzelinia sclerotiorum. Phytopathology 65:300-309.

2. Abawi, G. S., and Grogan, R. G. 1979. Epidemiology of diseases caused by Sclerotinia species. Phytopathology 69:899-904.

3. Adams, P. B., and Ayers, W. A. 1979. Ecology of Sclerotinia species. Phytopathology 69:896-899.

4. Ash, C. L. 1996. White mold of vegetables and ornamentals. North Dakota State Univ. Ext. Serv. Rep. No. 899.

5. Atallah, Z. K., Larget, B., Chen, X., and Johnson, D. A. 2004. High genetic diversity, phenotypic uniformity, and evidence of outcrossing in Sclerotinia sclerotiorum in the Columbia Basin of Washington State. Phytopathology 94:737-742.

6. Bilskie, J. 2001. Soil water status: Content and potential. Campbell Scientific, Inc. App. Note 2S-1.

7. Boland, G. J., and Hall, R. 1987. Epidemiology of white mould of white bean in Ontario. Can. J. Plant Pathol. 9:218-224.

8. Boland, G. J., and Hall, R. 1994. Index of plant hosts of Sclerotinia sclerotiorum. Can. J. Plant Pathol. 16:93-108.

9. Bom, M., and Boland, G. L. 2000. Evaluation of disease forecasting variables for Sclerotinia stem rot (Sclerotinia sclerotiorum) of canola. Can. J. Plant Sci. 80:889-898.

10. Brown, R. 2003. Soil texture. Univ. Fla. Ext. Serv. Fact Sheet No. SL-29.

11. Campbell, C. L., and Madden, L. V. 1999. Introduction to Plant Disease Epidemiology. John Wiley and Sons, New York.

12. Clarkson, J. P., Phelps, K., Whipps, J. M., Young, C. S., Smith, J. A., and Watling, M. 2004. Forecasting Sclerotinia disease on lettuce: toward developing a prediction model for carpogenic germination of sclerotia. Phytopathology 94:268-279.

13. del Río, L. E., Bradley, C. A., Henson, R. A., Endres, G. J., Hanson, B. K., McKay, K., Halvorson, M., Porter, P. M., Le Gare, D. G., and Lamey, H. A. 2007. Impact of Sclerotinia stem rot on yield of canola. Plant Dis. 91:191194.

14. Dillard, H. R., Ludwig, J. W., and Hunter, J. E. 1995. Conditioning sclerotia of Sclerotinia sclerotiorum for carpogenic germination. Plant Dis. 79:411415.

15. Ferraz, L. C. L., Cafe, A. C., Nasser, L. C. B., and Azevedo, J. 1999. Effects of soil moisture, organic matter and grass mulching on the carpogenic germination of sclerotia and infection of bean by Sclerotinia sclerotiorum Plant Pathol. 48:77-82.

16. Gee, G. W., and Bauder, J. W. 1979. Particle size analysis by hydrometer: a simplified method for routine textural analysis and a sensitivity test of measurement parameters. Soil Sci. Soc. Am. J. 43:1004-1007.

17. Hao, J. J., Subbarao, K. V., and Duniway, J. M. 2003. Germination of Sclerotinia minor and $S$. sclerotiorum sclerotia under various soil moisture and temperature combinations. Phytopathology 93:443-450.

18. Harikrishnan, R., and del Río, L. E. 2006. Influence of temperature, relative humidity, ascospore concentration, and length of drying of colonized dry bean flowers on white mold development. Plant Dis. 90:946-950.

19. Huang, H. C., Chang, C., and Kozub, G. C. 1998. Effect of temperature during sclerotial formation, sclerotial dryness, and relative humidity on myceliogenic germination of sclerotia of Sclerotinia sclerotiorum. Can. J. Bot. 76:494-499.

20. Huang, H. C., and Kozub, G. C. 1991. Temperature requirements for carpogenic germination of sclerotia of Sclerotinia sclerotiorum isolates of different geographic origin. Bot. Bull. Acad. Sin. 32:279-286.

21. Kohli, Y., Brunner, L. J., Yoell, H., Milgroom, M. G., Anderson, J. B., Morrall, R. A., and Kohn, L. M. 1995. Clonal dispersal and spatial mixing in populations of the plant pathogenic fungus, Sclerotinia sclerotiorum. Mol. Ecol. 4:69-77.

22. Kora, C., McDonald, M. R., and Boland, G. J. 2005. Occurrence of fungal pathogens of carrots on wooden boxes used for storage. Plant Pathol. 54:665-670.

23. Mila, A. L., and Yang, X. B. 2008. Effects of fluctuating soil temperature and water potential on sclerotia germination and apothecial production of Sclerotinia sclerotiorum. Plant Dis. 92:78-82.

24. Nepal, A. 2009. Role of moisture and soil texture on apothecia formation by Sclerotinia sclerotiorum (Lib.) de Bary. MS. Thesis, North Dakota State University, Fargo.

25. Qandah, I. S. 2008. Epidemiological studies on Sclerotinia stem rot of canola. Ph.D. dissertation, North Dakota State University, Fargo.

26. Qandah, I. S., and del Río, L. E. 2011. Temporal dispersal patterns of Sclerotinia sclerotiorum ascospores during canola flowering. Can. J. Plant Pathol. 33:159-167.

27. Richards, L. A., and Fireman, M. 1943. Pressure-plate apparatus for 
measuring moisture sorption and transmission by soils. Soil Sci. 56:395404.

28. Schaap, M. G. 1999. Rosetta Version 1.0. U.S. Salinity Laboratory, Riverside, CA. http://www.ars.usda.gov/Service/docs.htm?docid=8953

29. Schaap, M. G., Leij, F. J., and van Genuchten, M. T. 2001. ROSETTA: A computer program for estimating soil hydraulic parameters with hierarchical pedotransfer functions. J. Hydrol. 251:163-176.

30. Schwartz, H. F., and Steadman, J. R. 1978. Factors affecting sclerotia populations of, and apothecium production by Sclerotinia sclerotiorum. Phytopathology 68:383-388.

31. Sexton, A. C., and Howlett, B. J. 2004. Microsatellite markers reveal ge- netic differentiation among populations of Sclerotinia sclerotiorum from Australian canola fields. Curr. Genet. 46:357-365.

32. Sun, P., and Yang, X. B. 2000. Light, temperature, and moisture effects on apothecium production of Sclerotinia sclerotiorum. Plant Dis. 84:12871293.

33. van Genuchten, M. T. 1980. A closed-form equation for predicting the hydraulic conductivity of unsaturated soils. Soil Sci. Soc. Am. J. 44:892 898.

34. Wu, B. M., and Subbarao, K. V. 2008. Effects of soil temperature, moisture, and burial depths on carpogenic germination of Sclerotinia sclerotiorum and S. minor. Phytopathology 98:1144-1152. 